\title{
Comparison of Microalgae Cultivation in Photobioreactor, Open Raceway Pond, and a Two-Stage Hybrid System
}

\author{
Rakesh R. Narala ${ }^{\dagger}$, Sourabh Garg ${ }^{\dagger}$, Kalpesh K. Sharma, Skye R. Thomas-Hall, \\ Miklos Deme, Yan Li and Peer M. Schenk*
}

Algae Biotechnology Laboratory, School of Agriculture and Food Sciences, The University of Queensland, Brisbane, QLD, Australia

OPEN ACCESS

Edited by:

Arumugam Muthu,

Council of Scientific and Industrial

Research, India

Reviewed by:

Maria Gonzalez Alriols,

University of the Basque

Country, Spain

Jennifer Stewart,

University of Delaware, USA

*Correspondence:

Peer M. Schenk

p.schenk@uq.edu.au

${ }^{t}$ Rakesh R. Narala and

Sourabh Garg contributed equally.

Specialty section:

This article was submitted to

Bioenergy and Biofuels,

a section of the journal

Frontiers in Energy Research

Received: 02 May 2016

Accepted: 11 July 2016

Published: 02 August 2016

Citation:

Narala RR, Garg S, Sharma KK, Thomas-Hall SR, Deme M, Li Y and Schenk PM (2016) Comparison of

Microalgae Cultivation in

Photobioreactor, Open Raceway

Pond, and a Two-Stage Hybrid

System.

Front. Energy Res. 4:29.

doi: 10.3389/fenrg.2016.00029
In the wake of intensive fossil fuel usage and $\mathrm{CO}_{2}$ accumulation in the environment, research is targeted toward sustainable alternate bioenergy that can suffice the growing need for fuel and also that leaves a minimal carbon footprint. Oil production from microalgae can potentially be carried out more efficiently, leaving a smaller footprint and without competing for arable land or biodiverse landscapes. However, current algae cultivation systems and lipid induction processes must be significantly improved and are threatened by contamination with other algae or algal grazers. To address this issue, we have developed an efficient two-stage cultivation system using the marine microalga Tetraselmis sp. M8. This hybrid system combines exponential biomass production in positive pressure air lift-driven bioreactors with a separate synchronized high-lipid induction phase in nutrient deplete open raceway ponds. A comparison to either bioreactor or open raceway pond cultivation system suggests that this process potentially leads to significantly higher productivity of algal lipids. Nutrients are only added to the closed bioreactors, while open raceway ponds have turnovers of only a few days, thus reducing the issue of microalgal grazers.

Keywords: biodiesel, lipid induction, microalgae cultivation, microalgal oil, open pond, photobioreactor

\section{INTRODUCTION}

Microalgae are considered a promising feedstock for next-generation biofuel production because they are potentially 10-20 times more productive than any other biofuel crop and their large-scale cultivation does not need to compete for arable land or precious biodiverse landscapes (Hannon et al., 2010; Mata et al., 2010; Ahmad et al., 2011; Ndimba et al., 2013). Importantly, they are also able to grow in saline and even wastewater (Brennan and Owende, 2010; Christenson and Sims, 2011; Abou-Shanab et al., 2013). Microalgal oil is a valuable commodity, for example, when used as a substitute for omega-3-rich fish oil. However, commercial cultivation of microalgae for biodiesel, a relatively low-value product, requires further improvements to reach economical feasibility.

Microalgae accumulate large amounts of lipid bodies containing triacylglycerides under adverse conditions, such as during nutrient deprivation (Hu et al., 2008; Sharma et al., 2012). Under these circumstances, microalgae stop dividing but are still able to perform photosynthesis and the 
accumulation of triacylglycerides is considered a survival strategy to endure adverse conditions (Schenk et al., 2008; Breuer et al., 2012; Liu and Benning, 2013). Cultivation of microalgae for biodiesel production, however, aims at maximizing lipid productivity (or lipid yields) which takes both, growth rates and lipid contents, into consideration. In batch cultivation systems, microalgae are first grown exponentially to increase their biomass that is then followed by a lipid induction process, usually by omitting nutrient supply toward the end of the growth phase. Other lipid induction techniques are also available and their combination may lead to improved lipid contents (Sharma et al., 2012).

The two most common methods of microalgae cultivation are open cultivation systems, such as open ponds, tanks, and raceway ponds, and controlled closed cultivation systems using different types of bioreactors. One of the first attempts to scale up and cultivate microalgae was achieved using open raceway ponds (Johnson et al., 1988). Since then, extensive research has been carried out to cultivate microalgae in open cultivation systems. Some of the major advantages of an open cultivation system are minimal capital and operating costs, and a lower energy requirement for culture mixing. On the downside, open systems require large areas to scale up and are susceptible to contamination (e.g., introduced by birds) and adverse weather conditions. Although rarely reported, we know from our own experience that contamination with other microalgae, high bacterial loads, and grazers is common in large-scale open pond cultivation systems. In particular, we have experienced the damaging effects of the occurrence of rotifers to cultures of Tetraselmis, Chlorella, Nannochloropsis, and Scenedesmus, and the damage of amoeba to diatoms, which can be consumed in as little as 2 days after visual detection of contamination. Also in open pond systems, it is difficult to have control over growth parameters, such as evaporation, culture temperature, etc. (Oyler, 2009; Rupprecht, 2009; Mata et al., 2010).

Closed cultivation systems, here referred to as closed photobioreactors (PBRs), are more efficient in terms of quality as they can be operated at highly controlled conditions and, therefore, can overcome the disadvantages of an open cultivation system. PBRs can be designed and optimized in accordance with the strain of choice. This closed system utilizes relatively little space, while increasing the light availability and greatly decreasing the contamination issues. However, PBRs also have some disadvantages, such as bio-fouling, overheating, benthic algae growth, cleaning issues and high build-up of dissolved oxygen resulting in growth limitation, and, more importantly, very high capital costs for designing and operating (Molina Grima et al., 1999; Chisti, 2008).

The design and principle of cultivation systems change based on the specific needs (Schenk et al., 2008). Open ponds built in a wastewater treatment plant can be circular in shape or driven by gravity flow. Similarly, the basic tubular design of PBRs has been improved over the past decade to facilitate better light availability and culture mixing to produce a range of pharmaceutical products to high value nutritional products. PBRs were found to be more efficient when operated with continuous cultures (Otero and Fábregas, 1997; Mata et al., 2010). Continuous cultures in closed systems can be used for higher biomass productivity, but cannot be used for lipid induction by stress mechanisms (nutrient starvation) to produce biodiesel.

Although extensive studies have been carried out on open and closed cultivation methods, limited work has been carried out on two-stage hybrid cultivation systems. Two-phase hybrid cultivation systems have been proposed as an advantageous microalgae cultivation system, as they are able to essentially separate biomass growth from the lipid accumulation phase (Olaizola, 2000; Schenk et al., 2008; Su et al., 2011). Recently, a life cycle analysis demonstrated a considerably reduced environmental impact when comparing various open and closed cultivation systems with hybrid cultivation (Adesanya et al., 2014). A recent study on large-scale hybrid cultivation concluded that PBRs were economical to provide a continuous and consistent inoculum for short-period batch open pond cultures that prevented biological system crashes compared to longer term open pond cultures (Huntley et al., 2015).

To test whether productivity may also vary for these different systems, a side-by-side comparison was carried out in the present study, using the same algal culture. A new airlift-driven low-cost tubular PBR was designed and used for continuous growth phase of the microalgal culture while an open raceway pond was used for stress induction and synchronized lipid accumulation. A pilot-scale hybrid cultivation system has been constructed where microalgal growth for lipid production was compared to cultivation in either closed airlift-driven tubular PBR or open raceway ponds. The proposed hybrid cultivation system allows for a separate lipid accumulation phase where one or more efficient stress induction techniques can be carried out, while effectively avoiding the issue of contamination. Key parameters, such as sunlight, nutrients, $\mathrm{CO}_{2}$ and water, which affect outdoor cultivation of microalgae, were examined and monitored over time to understand the importance of these various factors for growth and lipid productivity.

\section{MATERIALS AND METHODS}

\section{Microalgae Cultivation and Analyses}

Strain Tetraselmis sp. M8 had previously been shown to accumulate significant amounts of lipids after nutrient deprivation (Lim et al., 2012). It was collected in an intertidal rock pool at Maroochydore, Australia (26 39'39"S $\left.153^{\circ} 6^{\prime} 18^{\prime \prime} \mathrm{E}\right)$. Pure Tetraselmis sp. M8 cultures were grown in $\mathrm{f} / 2$ medium $\left(\right.$ AlgaBoost ${ }^{\mathrm{TN}}$ ) with the omission of silica (f/2 (-Si); Guillard, 1975) in autoclaved seawater (collected at Cleveland, Brisbane, QLD, Australia) using laboratory culturing conditions described previously (Lim et al., 2012). A hemocytometer (Bright Line, Sigma-Aldrich, St. Louis, MO, USA) was used to count microalgal cells manually. A total of $100 \mu \mathrm{L}$ of culture was transferred into an Eppendorf tube and $0.1 \mu \mathrm{L}$ of acetic acid was added to ensure that the algae lose their motility. Growth rate and doubling time were calculated using the formulae mentioned below (Lim et al., 2012)

$$
\text { Growth rate }\left(\mathrm{K}^{\prime}\right)=\operatorname{Ln}\left(\frac{N 2 / N 1}{t 2-t 1}\right)
$$




$$
\text { Doubling time }=\frac{1}{k^{\prime} / \operatorname{Ln}(2)}
$$

where, $\mathrm{K}^{\prime}$ = growth rate,

$N 1$ and $N 2=$ biomass at time $1(t 1)$ and time $2(t 2)$, respectively.

Mean growth rates for the entire length of each growing cycle were determined based on cell concentrations at start and finish of each cycle. Nitrate and phosphate concentrations were measured in seawater using API Nutrient testing kits (API Fishcare, UK) according to the manufacturer's instructions.

\section{Culture Scale-Up and Monitoring}

A $50 \mathrm{~mL}$ preculture of pure Tetraselmis sp. M8 was used to inoculate a 2-L glass bottle and culture was made up to $1 \mathrm{~L}$ with fresh autoclaved seawater containing f/2 (-Si) medium. Filtered air was supplied through a Millipore syringe filter for uniform mixing of the culture and to prevent stagnation at the bottom of the bottle. The set-up was undisturbed for 4 days. At the end of the fourth day, $250 \mathrm{~mL}$ of the culture was transferred into a clear hanging polyethylene bag $(80 \mathrm{~cm} \times 50 \mathrm{~cm})$ which contained $4.75 \mathrm{~L}$ of fresh $\mathrm{f} / 2(-\mathrm{Si})$ medium in autoclaved seawater. Filtered air was supplied through a Millipore filter for mixing. The set-up was undisturbed for 4 days.

Four polyethylene bags were set up under outdoor conditions (roof structure of a three-storey building; Goddard building 8, University of Queensland St Lucia campus, Brisbane, QLD, Australia) and were each filled with $19 \mathrm{~L}$ of fresh $\mathrm{f} / 2(-\mathrm{Si})$ medium in seawater. The $5 \mathrm{~L}$ culture grown in the laboratory was mixed uniformly and $1 \mathrm{~L}$ was added to each $19 \mathrm{~L}$ bag. These outdoor cultures were left under direct sunlight for 4 days to achieve maximum cell density. The algal cultures of the four bags were then used for inoculation of a closed PBR that contained 1,200 L fresh $\mathrm{f} / 2(-\mathrm{Si})$ medium in seawater. $\mathrm{CO}_{2}(100 \%)$ was supplied to the PBR to control the $\mathrm{pH}$ at around 8.4 using a Weipro $\mathrm{pH}$ 2010 controller. This culture served as the starting culture for all subsequent experiments described in the section "Results".

Cell densities and nutrients were monitored on a daily basis using $5 \mathrm{~mL}$ samples of culture from the closed PBR or raceway ponds. Daily sampling was carried out at 04:00 p.m. (AEST). f/2 $(-\mathrm{Si})$ nutrients were added when required (nutrients depleted to less than 10\%). In the PBR and raceway pond, starvation phase was started once the cells attained a density of $1.5 \times 10^{6}$ cells/ $\mathrm{mL}$. Half the volume was harvested after the nutrients were completely used and the cell density exceeding $2.0 \times 10^{6}$ cells $/ \mathrm{mL}$. In hybrid system cultivation, when the desired PBR cell density of over $2 \times 10^{6}$ cells $/ \mathrm{mL}$ was reached, typically half the volume of the PBR (600 L) was transferred into the open raceway pond for lipid induction for 3-4 days and the removed volume of the PBR was replaced with fresh $\mathrm{f} / 2(-\mathrm{Si})$ medium in seawater. Apart from this sampling, climate data were obtained from Australia's Bureau of Meteorology, including temperature and solar exposure. PBR and raceway pond cultivation systems were tested simultaneously, but separately from hybrid cultivation. Both cultivation systems were cleaned and sanitized with bleach before cultivation. Cell count, temperature, and solar exposure values were plotted on graphs for the open raceway pond, the closed PBR and the hybrid cultivation system. To avoid biofilm formation in the PBR that could cause light limitation, the polyethylene tubes were occasionally (once a week) slapped to loosen any benthic cells. Nile red staining was performed as described previously (Lim et al., 2012). Data were analyzed statistically using one-way ANOVA followed by Tukey's test.

\section{RESULTS}

\section{Design and Construction of Pilot-Scale Photobioreactor and Raceway Ponds}

A closed tubular PBR and an open raceway pond were designed for side-by-side pilot-scale outdoor algae cultivation using an airlift mechanism for mixing. The volume of the PBR was $1,200 \mathrm{~L}$ and the raceway pond held 1,000 L, as shown in Figures $\mathbf{1}$ and 2 . The surface area of the PBR and each raceway pond was 4.6 and $6 \mathrm{~m}^{2}$, respectively. For a direct comparison of both cultivation systems, PBR and open raceway pond were used for simultaneous side-by-side algae cultivation. This included cycles of growth and lipid induction before harvesting of biomass. Synchronized lipid induction was verified by Nile red staining before harvesting (Figure 3) and only when lipid-rich biomass was produced it was harvested. The following paragraphs describe the cultivation cycles applied and monitored for each cultivation system.

\section{Outdoor Photobioreactor Cultivation}

Cell counts (cells/milliliter) and all other parameters of PBRgrown Tetraselmis sp. M8 culture were recorded for 33 days,

A

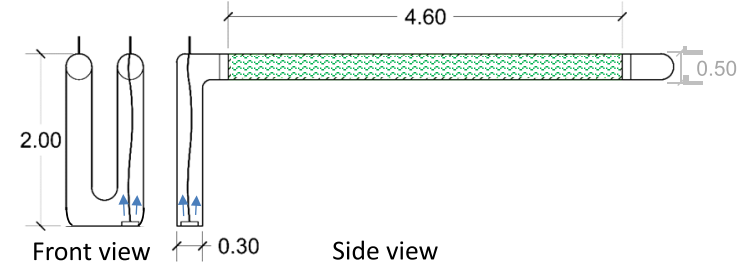

B

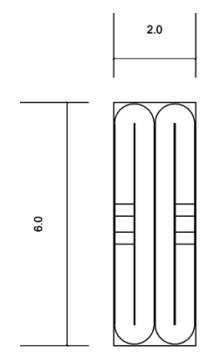

Top view

Side view

FIGURE 1 | Design and specifications of pilot-scale (A) tubular PBR (1:35 scale) and (B) two open raceway ponds (1:75 scale). A 2-m-long U-shaped PVC pipe with $0.3 \mathrm{~m}$ diameter was used as the airlift for the PBR that was connected to clear $4.6 \mathrm{~m}$ polyethylene flexible tubes that were also connected to a PVC bend at the end. Two 6-m-long open raceway ponds were constructed using fiberglass-coated plywood. Mixing was achieved by aeration with pressurized air using airlifts (arrows). This included an aeration disk with 6000 exit holes for the PBR and a single exit point for pressured air at a lowered section of the raceway ponds. Specifications are shown in meters. 


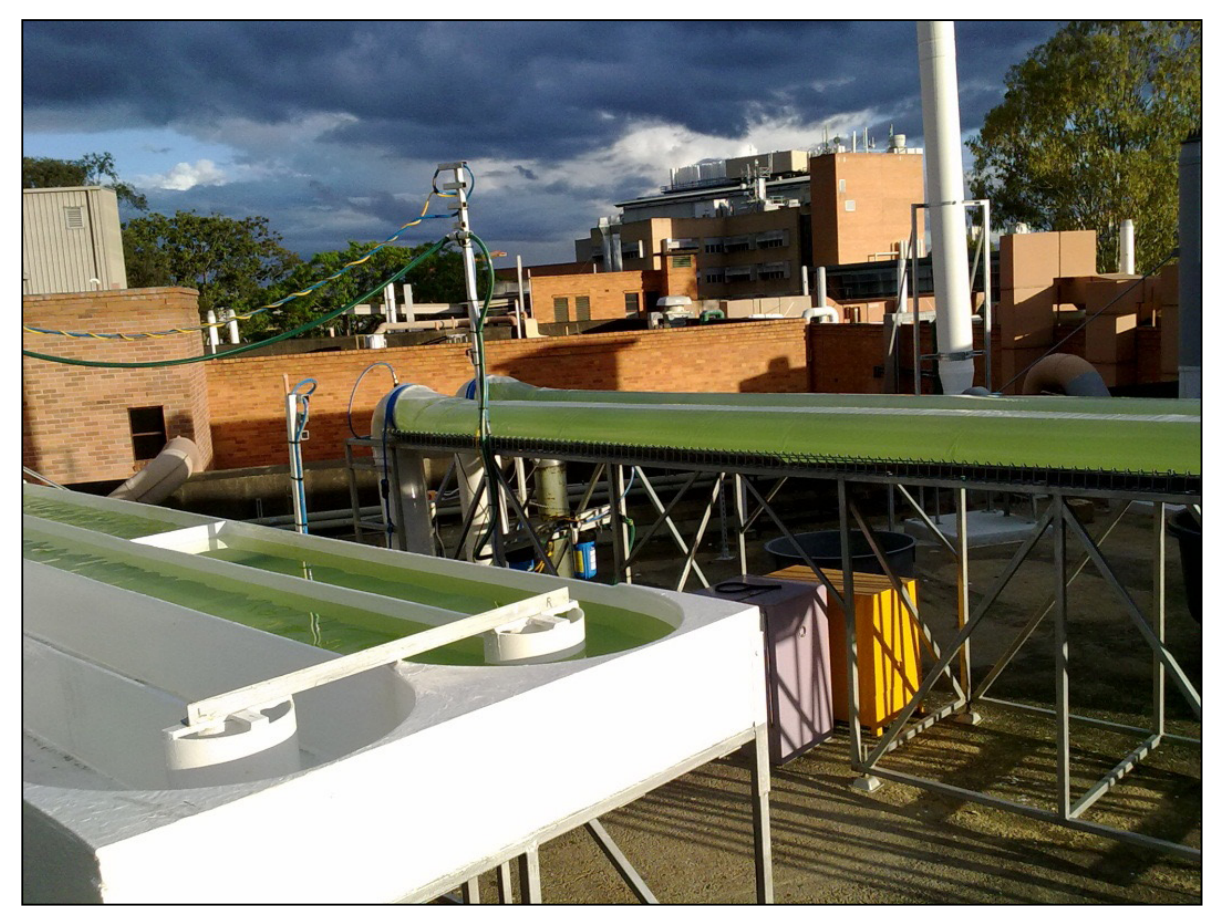

FIGURE 2 | Photograph of pilot-scale two-stage microalgae cultivation system. Individual modules were used for single testing of photobioreactor or open ponds.
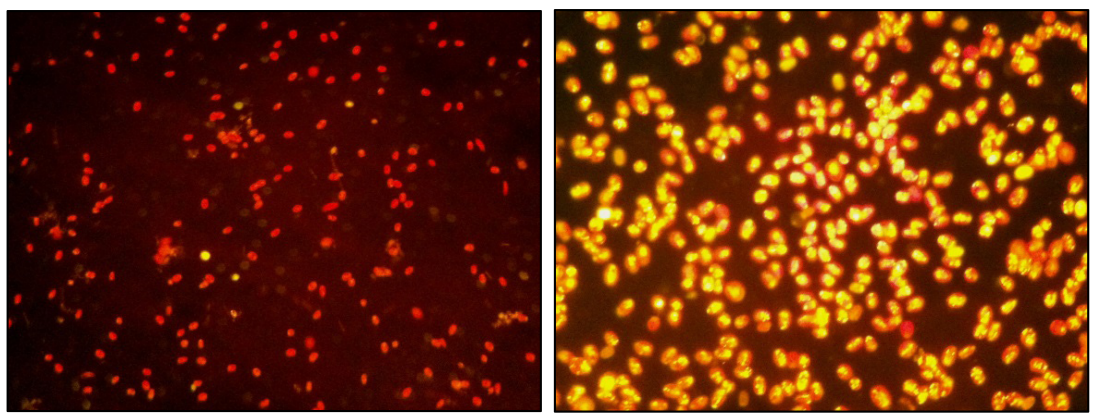

FIGURE 3 | Two Nile red-stained samples of Tetraselmis sp. M8 culture (40x magnification) before (left) and after nutrient deprivation stress at the time of harvesting (right).

which underwent several growth and harvesting cycles (Figure 4). Only biomass verified to be rich in lipids was harvested. The first cycle started with exponential growth after day 6 and nutrient stress set in on day 8 . Nile red staining was performed on the following days to monitor the lipid induction. Low sunlight was recorded on day 10 followed by a decrease in lipids and cell numbers on day 11 . Fresh $\mathrm{f} / 2(-\mathrm{Si})$ medium was added on day 12 and half of the culture volume $(600 \mathrm{~L})$ was harvested on day 13. Similarly, nutrient stress set in on day 20 during the second growth cycle and half of the culture was harvested again on day 23 . The third growth cycle achieved maximum cell density on day 32 with accumulated lipid content, but declined in cell numbers on day 33. The entire culture was harvested.

\section{Open Raceway Pond Cultivation}

Cultivation in the raceway pond led to three harvesting events on days 13, 23, and 33 over the same time period (Figure 4). Similar to the first growth cycle in the PBR, nutrient stress was measured on day 8 and the culture reached a density of $2 \times 10^{6}$ cells $/ \mathrm{mL}$ followed by a decline in density on day $12 . \mathrm{f} / 2(-\mathrm{Si})$ nutrients were added and half the volume $(500 \mathrm{~L})$ was harvested. On day 23 , the cell density reached $2.3 \times 10^{6}$ cells $/ \mathrm{mL}$ after nutrient stress from days 20 to 22 . Maximum cell densities were observed on days 27 and 28. The culture was nutrient-stressed during the following 2 days and the cell density was $2.8 \times 10^{6}$ cells $/ \mathrm{mL}$ on day 32 with substantial lipid accumulation. Hence, all the culture was harvested. 

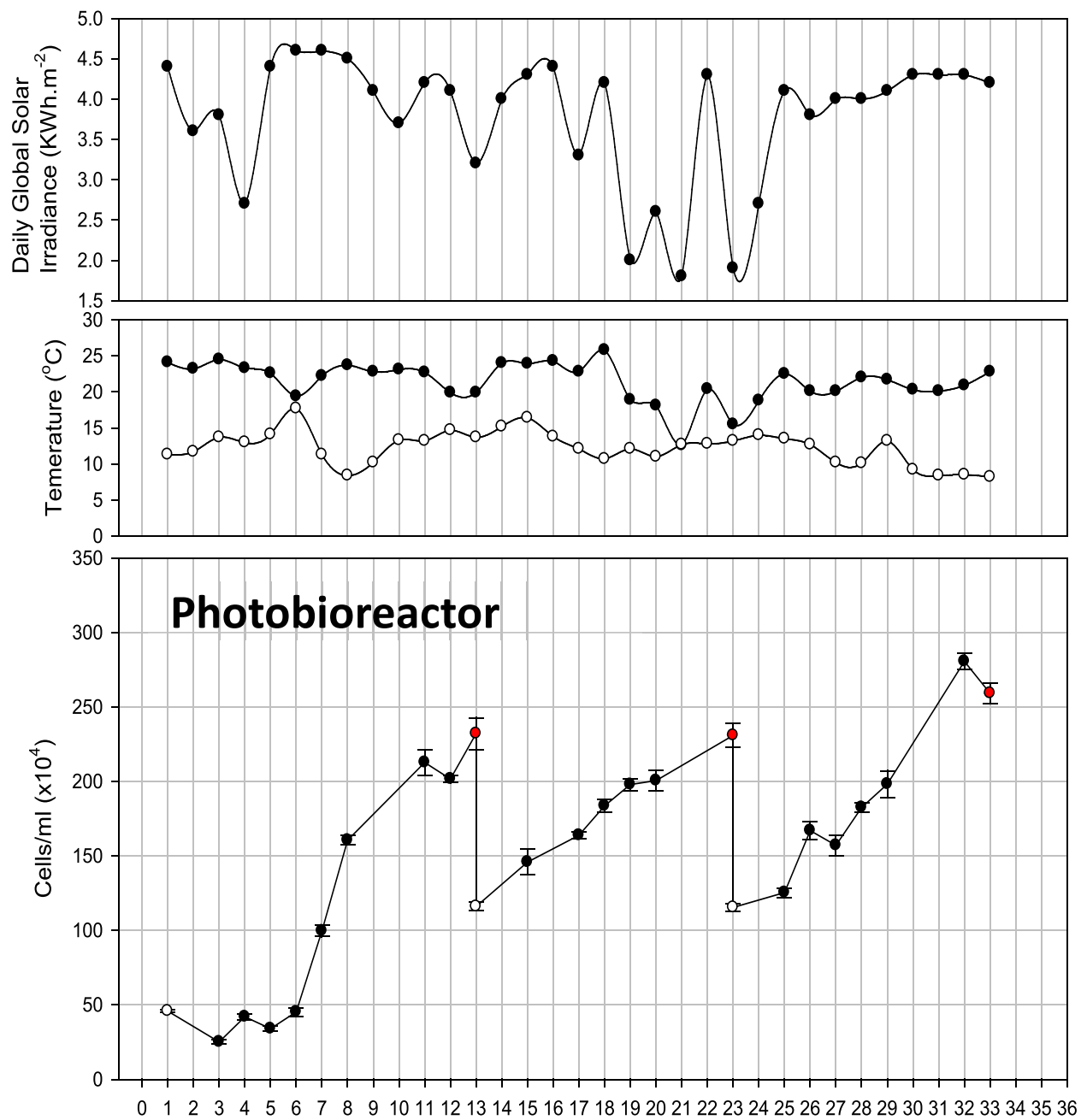

$0 \begin{array}{llllllllllllll}2 & 3 & 4 & 5 & 6 & 7 & 8 & 9 & 1011 & 12131415161718192021222324252627282930313233343536\end{array}$

Days

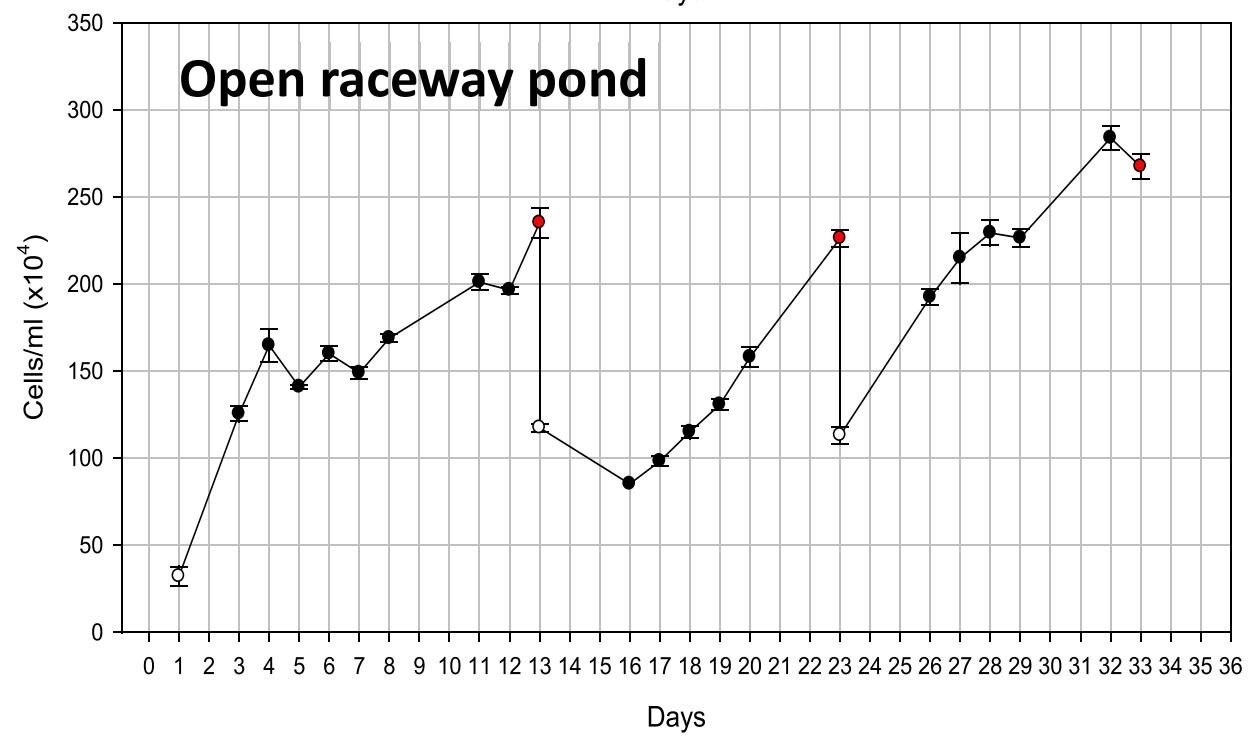

FIGURE 4 | Observations of photobioreactor and open raceway pond cultivation for $\mathbf{3 3}$ days. Also shown is daily global solar irradiance, as well as minimum and maximum air temperature recorded for the respective day. White and red dots represent the start and finish of each cycle. 


\section{Two-Stage Hybrid Cultivation System}

A two-stage hybrid cultivation system was applied by transferring a portion of rapidly growing cells from the PBR to open raceway ponds where then nutrients diminished and algae were harvested upon lipid accumulation. Figure 5 shows the cell density and various harvesting points in the PBR as part of the two-stage hybrid cultivation approach. During these harvesting events, at least half of the PBR culture volume was transferred to one of the raceway ponds, where lipid biosynthesis and accumulation was stimulated by nutrient depletion. The initial cell concentration of the PBR was $1.2 \times 10^{6}$ cells $/ \mathrm{mL}$. Initially it took 8 days for the medium to get exhausted and, during this cycle, the highest cell density was monitored (up to $3 \times 10^{6}$ cells $/ \mathrm{mL}$ ). On day 8 , based on the high cell density, $900 \mathrm{~L}$ of the culture was transferred into the raceway pond for lipid induction. The PBR was refilled with medium for the second cycle. The duration of the second cycle was 7 days in the PBR followed by raceway pond cultivation for lipid induction. For the third cycle, as the cell density was $1.9 \times 10^{6}$ cells $/ \mathrm{mL}$ and the nutrient concentration was below detection limit, half (600 L) of the culture was transferred into the raceway pond only after
4 days. During the last three cycles, microalgae were cultured in the closed PBR for 5, 6, and 6 days, respectively, followed by 3-4 days each of starvation in the raceway pond.

\section{Comparison of Individual Open Pond or Closed PBR Cultivation with Two-Stage Hybrid Cultivation System}

Both, closed PBR and open raceway pond cultivation resulted in three main growth cycles and harvesting events (Figure 4). Only biomass verified to be rich in lipids was harvested. Considering the growth curves for closed PBR and open raceway pond (Figure 4), a possible forth harvest appeared possible when cell concentrations reached $2 \times 10^{6} / \mathrm{mL}$ at days 28 and 29 , respectively, but the biomass during this high irradiation phase was not rich in lipids and had, therefore, be harvested a few days later. During the same amount of time, the hybrid cultivation system led to six main growth cycles and harvesting events (Figure 5). Accordingly, the average growth rate of the hybrid system was significantly higher than that of both single
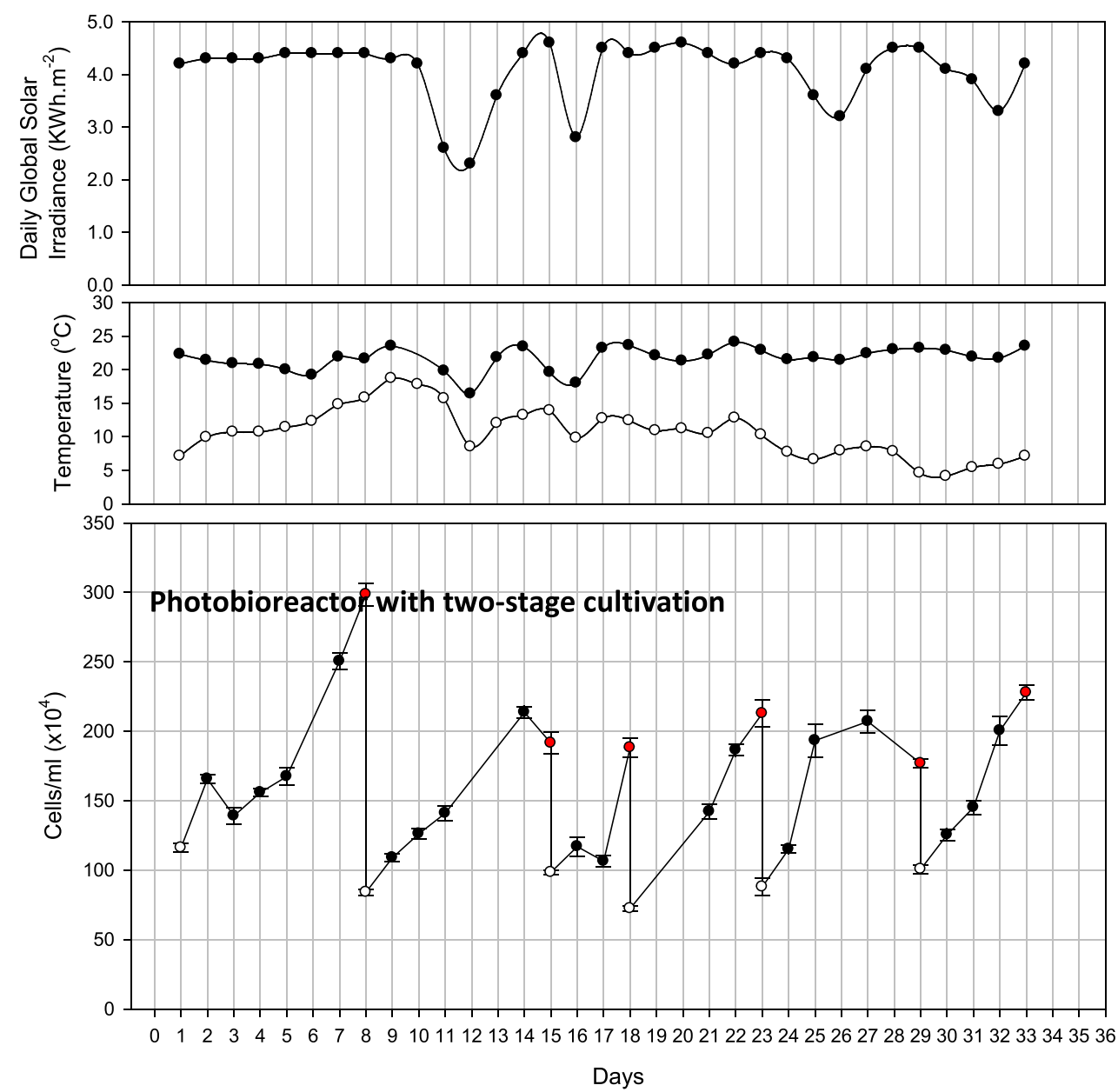

FIGURE 5 | Observations of closed photobioreactor for two-stage cultivation for $\mathbf{3 5}$ days. Also shown is daily global solar irradiance, as well as minimum and maximum air temperature recorded for the respective day. White and red dots represent the start and finish of each cycle. 

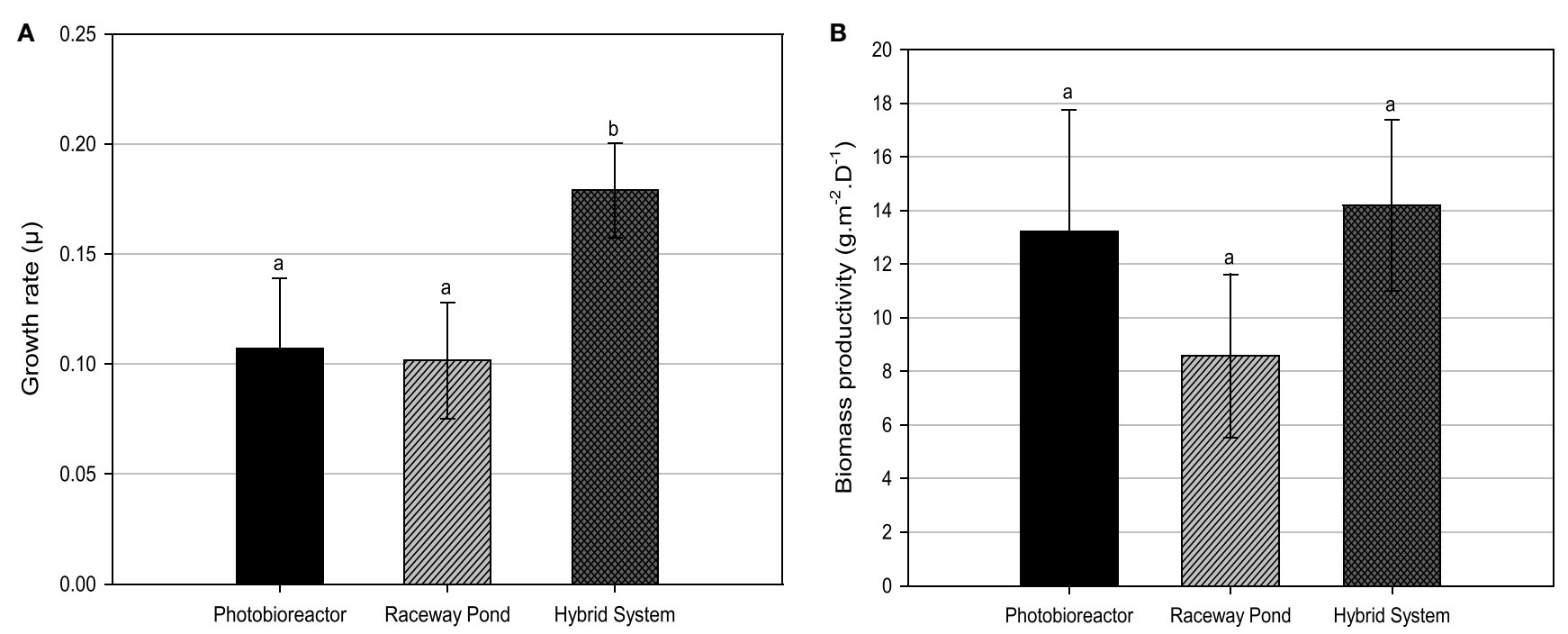

FIGURE 6 | (A) Growth rates and (B) biomass productivities for different cultivation systems. Different letters show statistically significant differences $(P<0.05)$.

systems (Figure 6A). The main reason for this appears to be that biomass growth and lipid induction phases are essentially independent from each other when using the hybrid cultivation system. This enables to keep the culture in rapid growth at a very high cell density. On the other hand, microalgal cultures in individual cultivation systems (PBR or open raceway pond) go through phases of exponential growth and nutrient starvation to enable lipid accumulation, followed by a brief lag phase before the next growth phase, leading to reduced overall growth rates (Figure 4). To determine productivity of all systems, biomass harvests (presented as gram/square meter/day) over the duration of the experiments are shown in Figure 6B.

Since the average growth rate of hybrid cultivation cannot be directly compared to that of either closed PBR or raceway pond due to different weather conditions, especially solar irradiance, further analysis was carried out to normalize the areal productivity of lipid-rich biomass to the total solar irradiance that occurred during the testing periods (Figure 7). The biomass productivity relative to solar irradiance was significantly higher for the hybrid cultivation system compared to open ponds.

\section{DISCUSSION}

In the present study, three growth and harvesting cycles were carried out for a closed PBR and an open raceway pond, while for a similar duration, six cultivation cycles were achieved using a two-stage hybrid cultivation system. The higher number of growth and harvesting cycles in the hybrid system was based on the use of separate cultivation systems for biomass growth and lipid induction phases. As the culture in growth phase never ran critically low in nutrients, two separate systems helped maintain higher growth rates and lowered the chance of culture dormancy or contamination. It was hypothesized that a separation of growth phase and lipid induction would be advantageous because microalgae typically either divide to increase the cell numbers (usually during ideal nutrient replete conditions) or lipid biosynthesis will be initiated as a means to increase survival capability during adverse conditions, such as nutrient deprivation. The lipid accumulation capacity of Tetraselmis sp. M8 under these conditions has been previously described (Lim et al., 2012; Li et al., 2014; Sharma et al., 2014). Although lipids were not quantified in the present study, only lipid-rich biomass (checked by Nile red staining) after nutrient depletion phases was harvested to allow comparisons between cultivation systems. We found that nutrient deplete cultures during the lipid accumulation phase still underwent cell divisions, although at a lower rate.

Tetraselmis sp. M8 grown in the hybrid system had the highest average growth rate and, thus, the lowest doubling time (Figure 6A), while the increased biomass harvests compared to the open raceway pond was not significant (Figure 6B). To enable a direct comparison that takes into account the different weather conditions, the areal productivity of lipid-rich biomass was normalized to the total solar irradiance that occurred during the testing periods (Figure 7). This showed that the cultures in the hybrid cultivation produced significantly $(P<0.05)$ more lipid-rich biomass than the raceway cultivation system when normalized to solar exposure, while there was no significant difference in areal productivity between hybrid system and single-stage PBR. If assuming that the amount and quality of lipids did not differ between the cultivation systems and that all systems are at an equal level of the technological learning curve, this suggests, in principle, that hybrid cultivation systems should be preferred for the production of lipid-rich biomass. This should be weighed up against the increased capital expenditure and labor costs compared to simpler open pond systems and other possible advantages and disadvantages contrasted in Table 1.

A major advantage for hybrid systems can be expected for longer term cultivation where contamination by other algae or predators becomes a major concern. These problems occur 


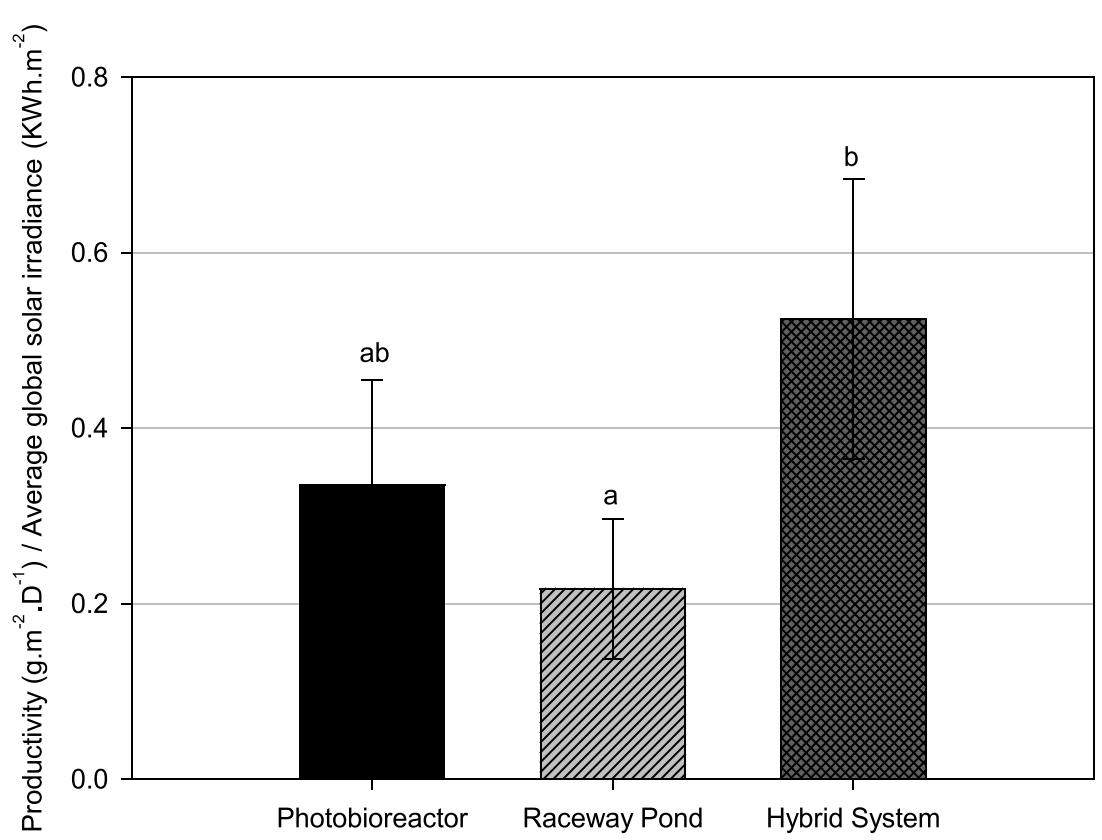

FIGURE 7 | Biomass productivity normalized to daily global solar exposure for different cultivation systems. Different letters show statistically significant differences $(P<0.05)$.

TABLE 1 | Comparison of various microalgae cultivating methods considering findings from the present and previous studies.

\begin{tabular}{llll}
\hline Factor & Photobioreactor & $\begin{array}{l}\text { Raceway } \\
\text { pond }\end{array}$ & $\begin{array}{l}\text { Hybrid } \\
\text { system }\end{array}$ \\
\hline $\begin{array}{l}\text { Space required } \\
\text { Evaporation loss }\end{array}$ & Moderate & High & High \\
$\mathrm{CO}_{2}$ sparging efficiency & High & High & Moderate \\
Maintenance & Difficult & Low & Moderate \\
Contamination risk & Low & Easy & Moderate \\
Biomass quality & Reproducible & High & Low \\
Energy input for mixing & High & Lowiable & Reproducible \\
Operation type & Batch & Batch & Moderate \\
Setup cost & High & Low & Montinuous \\
Maintaining continuous & Difficult & Difficult & Easy \\
exponential phase & & &
\end{tabular}

(Borowitzka, 1999; Barbosa et al., 2003; Moheimani and Borowitzka, 2006; Chisti, 2007; Huntley and Redalje, 2007; Eriksen, 2008; Ugwu et al., 2008; Brennan and Owende, 2010; Harun et al., 2010; Mata et al., 2010).

especially in open pond systems or during times of reduced algae growth (Moheimani and Borowitzka, 2006; Wang et al., 2013). During hybrid cultivation in the present study, the continuously grown culture was contained in a closed PBR that rarely experiences phases of reduced growth or stagnation, while contamination-prone open ponds only ever held cultures for a few days before being cleaned, therefore avoiding this critical issue.

The present study was a pilot study aimed at identifying the most suitable system for algae cultivation for lipid production. Productivities were relatively low under these unoptimized conditions. Higher yields can be expected if cultivation conditions are further improved, for example, by automated nutrient supply and automated harvesting based on cell density. Carefully dosed removal of cells during harvests is required to stay within the optimal window of exponential growth. Similarly, it may be advisable to harvest high cell density cultures when irradiance is expected to be low for the following days based on weather forecasts. This will avoid light limitations that may lead to reduced or stagnant growth or even partial culture death. Future studies should focus on long-term monitoring of these systems and use carefully optimized larger-scale demonstration facilities to enable reduction of operating costs, energy input, and environmental impact.

\section{CONCLUSION}

The comparison of microalgae cultivation systems, including open pond, closed PBR, and hybrid cultivation, suggests that the hybrid system is superior for the production of lipid-rich microalgae. The evaluated hybrid cultivation enables a separation of biomass growth and lipid induction phases, so that exponential biomass production and one or more efficient stress induction techniques can be carried out simultaneously, while effectively avoiding the issue of contamination. Technoeconomic analyses of large-scale production in hybrid cultivation mode will reveal whether this system is also economically more viable.

\section{AUTHOR CONTRIBUTIONS}

RN performed bioreactor and open pond experiments, collected and interpreted data, and contributed to the writing of this manuscript. SG performed bioreactor and open pond experiments, collected and interpreted data, and contributed to the writing of this 
manuscript. KS performed Tetraselmis laboratory experiments, collected and interpreted data, and contributed to the writing of this manuscript. ST-H designed experiments, interpreted data, and contributed of the writing of this manuscript. MD designed and constructed photobioreactor and open ponds, performed experiments, interpreted data, and contributed to the writing of this manuscript. YL designed experiments, interpreted data, and contributed to the writing of this manuscript. PS designed experiments, interpreted data, and contributed to the writing of this manuscript.

\section{REFERENCES}

Abou-Shanab, R. A. I., Ji, M.-K., Kim, H.-C., Paeng, K.-J., and Jeon, B.-H. (2013). Microalgal species growing on piggery wastewater as a valuable candidate for nutrient removal and biodiesel production. J. Environ. Manage. 115, 257-264. doi:10.1016/j.jenvman.2012.11.022

Adesanya, V. O., Cadena, E., Scott, S. A., and Smith, A. G. (2014). Life cycle assessment on microalgal biodiesel production using a hybrid cultivation system. Bioresour. Technol. 163, 343-355. doi:10.1016/j.biortech.2014. 04.051

Ahmad, A. L., Yasin, N. H. M., Derek, C. J. C., and Lim, J. K. (2011). Microalgae as a sustainable energy source for biodiesel production: a review. Renew. Sustain. Energy Rev. 15, 584-593. doi:10.1016/j.rser.2010.09.018

Barbosa, M. J., Albrecht, M., and Wijffels, R. H. (2003). Hydrodynamic stress and lethal events in sparged microalgae cultures. Biotechnol. Bioeng. 83, 112-120. doi:10.1002/bit.10657

Borowitzka, M. B. (1999). Commercial production of microalgae: ponds, tanks, tubes and fermenters. J. Biotechnol. 70, 313-321. doi:10.1016/ S0168-1656(99)00083-8

Brennan, L., and Owende, P. (2010). Biofuels from microalgae - a review of technologies for production, processing, and extractions of biofuels and co-products. Renew. Sustain. Energy Rev. 14, 557-577. doi:10.1016/j.rser.2009. 10.009

Breuer, G., Lamers, P. P., Martens, D. E., Draaisma, R. B., and Wijffels, R. H. (2012). The impact of nitrogen starvation on the dynamics of triacylglycerol accumulation in nine microalgae strains. Bioresour. Technol. 124, 217-226. doi:10.1016/j. biortech.2012.08.003

Chisti, Y. (2007). Biodiesel from microalgae. Biotechnol. Adv. 25, 294-306. doi:10.1016/j.biotechadv.2007.02.001

Chisti, Y. (2008). Biodiesel from microalgae beats bioethanol. Trends Biotechnol. 26, 126-131. doi:10.1016/j.tibtech.2007.12.002

Christenson, L., and Sims, R. (2011). Production and harvesting of microalgae for wastewater treatment, biofuels, and bioproducts. Biotechnol. Adv. 29, 686-702. doi:10.1016/j.biotechadv.2011.05.015

Eriksen, N. (2008). The technology of microalgal culturing. Biotechnol. Lett. 30, 1525-1536. doi:10.1007/s10529-008-9740-3

Guillard, R. R. L. (1975). "Culture of phytoplankton for feeding marine invertebrates," in Culture of Marine Invertebrate Animals, eds W. L. Smith and M. H. Chanley (New York: Plenum Press), 29-60.

Hannon, M., Gimpel, J., Tran, M., Rasala, B., and Mayfield, S. (2010). Biofuels from algae: challenges and potential. Biofuels 1, 763-784. doi:10.4155/bfs.10.44

Harun, R., Singh, M., Forde, G. M., and Danquah, M. K. (2010). Bioprocess engineering of microalgae to produce a variety of consumer products. Renew. Sustain. Energy Rev. 14, 1037-1047. doi:10.1016/j.rser.2009.11.004

Hu, Q., Sommerfeld, M., Jarvis, E., Ghirardi, M., Posewitz, M., Seibert, M., et al. (2008). Microalgal triacylglycerols as feedstocks for biofuel production: perspectives and advances. Plant J. 54, 621-639. doi:10.1111/j.1365-313X.2008. 03492.x

Huntley, M., and Redalje, D. (2007). $\mathrm{CO}_{2}$ mitigation and renewable oil from photosynthetic microbes: a new appraisal. Mitigat. Adapt. Strat. Global Change 12, 573-608. doi:10.1007/s11027-006-7304-1

Huntley, M. E., Johnson, Z. I., Brown, S. L., Sills, D. L., Gerber, L., Archibald, I., et al. (2015). Demonstrated large-scale production of marine microalgae for fuels and feed. Algal Res. 10, 249-265. doi:10.1016/j.algal.2015.04.016

\section{ACKNOWLEDGMENTS}

We wish to thank the Australian Research Council and North Queensland \& Pacific Biodiesel for financial support.

\section{FUNDING}

This work was financially supported by a linkage grant of the Australian Research Council and North Queensland \& Pacific Biodiesel (LP0990558).

Johnson, D. A., Weissman, J., and Goebel, R. (1988). An Outdoor Test Facility for the Large-scale Production of Microalgae (No. SERI/TP-231-3325; CONF-880215-4). Golden, CO, Fairfield, CA: Solar Energy Research Inst., Microbial Products, Inc.

Li, Y., Naghdi, F. G., Garg, S., Adarme-Vega, T. C., Thurecht, K. J., Ghafor, W. A., et al. (2014). A comparative study: the impact of different lipid extraction methods on current microalgal lipid research. Microb. Cell Fact. 13, 14. doi:10.1186/1475-2859-13-14

Lim, D. K., Garg, S., Timmins, M., Zhang, E. S., Thomas-Hall, S. R., Schuhmann, H., et al. (2012). Isolation and evaluation of oil-producing microalgae from subtropical coastal and brackish waters. PLoS ONE 7:e40751. doi:10.1371/journal. pone.0040751

Liu, B., and Benning, C. (2013). Lipid metabolism in microalgae distinguishes itself. Curr. Opin. Biotechnol. 24, 300-309. doi:10.1016/j.copbio.2012.08.008

Mata, T. M., Martins, A. A., and Caetano, N. S. (2010). Microalgae for biodiesel production and other applications: a review. Renew. Sustain. Energy Rev. 14, 217-232. doi:10.1016/j.rser.2009.07.020

Moheimani, N. R., and Borowitzka, M. A. (2006). The long-term culture of coccolithophore Pleurochrysis carterae (Haptophyta) in outdoor raceway ponds. J. Appl. Phycol. 18, 703-712. doi:10.1007/s10811-006-9075-1

Molina Grima, E., Fernández, F. G. A., García Camacho, F., and Chisti, Y. (1999). Photobioreactors: light regime, mass transfer, and scale-up. J. Biotechnol. 70, 231-247. doi:10.1016/S0168-1656(99)00078-4

Ndimba, B. K., Ndimba, R. J., Johnson, T. S., Waditee-Sirisattha, R., Baba, M., Sirisattha, S., et al. (2013). Biofuels as a sustainable energy source: an update of the applications of proteomics in bioenergy crops and algae. J. Proteomics 93, 234-244. doi:10.1016/j.jprot.2013.05.041

Olaizola, M. (2000). Commercial production of astaxanthin from Haematococcus pluvialis using 25,000-liter outdoor photobioreactors. J. Appl. Phycol. 12, 499-506. doi:10.1023/A:1008159127672

Otero, A., and Fábregas, J. (1997). Changes in the nutrient composition of Tetraselmis suecica cultured semicontinuously with different nutrient concentrations and renewal rates. Aquaculture 159, 111-123. doi:10.1016/S0044-8486 (97)00214-7

Oyler, J. R. (2009). Integrated Processes and Systems for Production of Biofuels Using Algae. Patent No. US20110136217 A1.

Rupprecht, J. (2009). From systems biology to fuel: Chlamydomonas reinhardtii as a model for a systems biology approach to improve biohydrogen production. J. Biotechnol. 142, 10-20. doi:10.1016/j.jbiotec.2009.02.008

Schenk, P. M., Thomas-Hall, S., Stephens, E., Marx, U., Mussgnug, J., Posten, C., et al. (2008). Second generation biofuels: high-efficiency microalgae for biodiesel production. BioEnergy Res. 1, 20-43. doi:10.1007/s12155-0089008-8

Sharma, K., Li, Y., and Schenk, P. M. (2014). UV-C mediated lipid induction and settling, a step change towards economical microalgae biodiesel production. Green Chem. 16, 3539-3548. doi:10.1039/C4GC00552J

Sharma, K. K., Schuhmann, H., and Schenk, P. M. (2012). High lipid induction in microalgae for biodiesel production. Energies 5, 1532-1553. doi:10.3390/ en5051532

Su, C.-H., Chien, L.-J., Gomes, J., Lin, Y.-S., Yu, Y.-K., Liou, J.-S., et al. (2011). Factors affecting lipid accumulation by Nannochloropsis oculata in a two-stage cultivation process. J. Appl. Phycol. 23, 903-908. doi:10.1007/s10811-010-9609-4

Ugwu, C. U., Aoyagi, H., and Uchiyama, H. (2008). Photobioreactors for mass cultivation of algae. Bioresour. Technol. 99, 4021-4028. doi:10.1016/j. biortech.2007.01.046 
Wang, H., Zhang, W., Chen, L., Wang, J., and Liu, T. (2013). The contamination and control of biological pollutants in mass cultivation of microalgae. Bioresour. Technol. 128, 745-750. doi:10.1016/j.biortech.2012.10.158

Conflict of Interest Statement: The authors declare that the research was conducted in the absence of any commercial or financial relationships that could be construed as a potential conflict of interest.
Copyright (c) 2016 Narala, Garg, Sharma, Thomas-Hall, Deme, Li and Schenk. This is an open-access article distributed under the terms of the Creative Commons Attribution License (CC BY). The use, distribution or reproduction in other forums is permitted, provided the original author(s) or licensor are credited and that the original publication in this journal is cited, in accordance with accepted academic practice. No use, distribution or reproduction is permitted which does not comply with these terms. 